\title{
1,3-Dipolarna cikloadicija (II. dio): Trokomponentne Cu(I) katalizirane klik-reakcije
}

DOI: $10.15255 /$ KUI.2014.019

KUI-30/2015

Pregledni rad

Prispjelo 8. srpnja 2014.

Prihvaćeno 2. rujna 2014.

L. Krstulović,a* D. Saftić, J. Matić, ${ }^{c}$ M. Bajić, i B. Žinićb

a Zavod za kemiju i biokemiju, Veterinarski fakultet, Sveučilište u Zagrebu, Heinzelova 55, 10000 Zagreb

b Laboratorij za supramolekularnu i nukleozidnu kemiju, Zavod za organsku kemiju i biokemiju, Institut Ruđer Bošković, Bijenička cesta 54, 10000 Zagreb

'Laboratorij za studij interakcija biomakromolekula, Zavod za organsku kemiju i

biokemiju,Institut Ruđer Bošković, Bijenička cesta 54, 10000 Zagreb

\author{
|| Sažetak \\ supstituenata na ishod reakcije. \\ \| Ključne riječi \\ Alkin, azid, klik-kemija, bakar, trokomponentna reakcija
}

$\mathrm{Cu}(\mathrm{I})$ kataliziranim reakcijama sulfonil- odnosno fosforil-azida i terminalnih alkina nastaje intermedijar ketenimin koji reagira s nukleofilima kao što su voda, alkoholi, amini, piroli ili indoli, pri čemu nastaju odgovarajući amidi, imidati, amidini i supstituirani heterocikli, u jednom reakcijskom koraku. Te selektivne reakcije zbivaju se pri blagim reakcijskim uvjetima (sobna temperatura, prisustvo zraka i vode), bez steričkog i elektronskog utjecaja

\section{Uvod}

Pojam klik-kemija uveli su 2001. godine Sharpless, Kolb i Finn, ${ }^{1}$ a podrazumijeva kemijske reakcije u kojima nastaju veze ugljikovih atoma s heteroatomima i u kojima se brzo i pouzdano dolazi do produkata spajanjem više manjih jedinica. Sharpless i sur. definirali su niz uvjeta koje reakcija treba zadovoljiti da bi se smatrala klik-reakcijom: široki raspon primjene, neškodljivi i lako uklonjivi nusprodukti, stereospecifičnost (ne nužno i enantioselektivnost), jednostavni reakcijski uvjeti, neosjetljivost na vodu i kisik, uporaba pristupačnih reagenasa i lako uklonjivih neškodljivih otapala, te nastanak stabilnog produkta u velikom iskorištenju uz jednostavnu izolaciju metodama kao što su kristalizacija i filtracija. lako je teško navesti reakciju koja zadovoljava baš sve navedene, gotovo idealne uvjete, u posljednjih deset godina raste broj poznatih klik-reakcija.

Meldal i Sharpless 2001. godine u reakciju 1,3-dipolarne cikloadicije azida 1 i terminalnih alkina 2 uvode bakar(I) kao katalizator. ${ }^{2} \mathrm{Cu}(\mathrm{I})$ katalizirana 1,3-dipolarna cikloadicija je mnogo brža od nekatalizirane Huisgenove ${ }^{3}$ cikloadicije, a odvija se pri temperaturama od 0 do $25{ }^{\circ} \mathrm{C}$. Sterička i elektronska svojstva supstituenata ne utječu bitno na tijek katalizirane reakcije. Reakcijom regioselektivno nastaju 1,4-disupstituirani 1,2,3-triazoli 3 (shema 1) koji su stabilni u hidrolitičkim i oksidoredukcijskim uvjetima te pri visokim temperaturama. $\mathrm{Cu}(\mathrm{I})$ katalizirana 1,3-dipolarna cikloadicija azida i alkina (krat. CuAAC engl. Copper (I) Catalysed Azide-Alkyne Cycloaddition) najzastupljenija je i najpoznatija klik-reakcija čiju primjenu, osim u sintetskoj organskoj kemiji, nalazimo i u medicinskoj kemiji i kemiji materijala. ${ }^{5}$

Sudjelovanjem sulfonil- ili fosforil-azida u $\mathrm{Cu}(\mathrm{I})$ kataliziranim klik-reakcijama nastaje reaktivni intermedijar ketenimin koji može reagirati s različitim nukleofilima dajući imidate, amide, amidine i supstituirane heterocikle. Ovaj rad daje uvid u mehanizam i raznovrsnost trokomponentnih $\mathrm{Cu}(\mathrm{I})$ kataliziranih klik-reakcija.

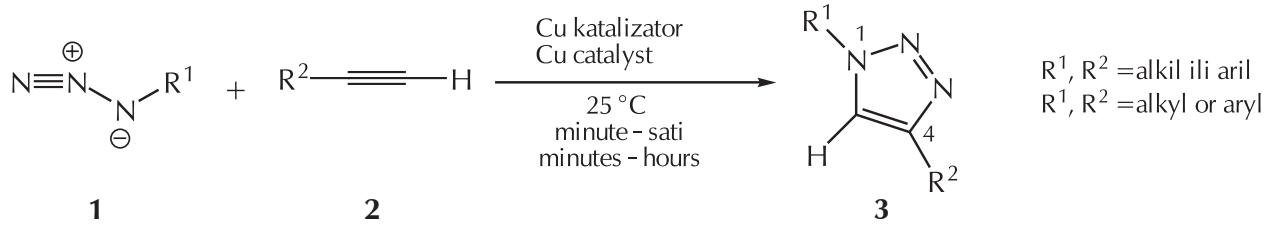

Shema 1 - Cu(I) katalizirana azid-alkinska cikloadicija Scheme 1 - Cu(I) catalysed azide-alkyne cycloaddition

\footnotetext{
*Autor za dopisivanje: Dr. sc. Luka Krstulović e-pošta: lkrstulovic@vef.hr
} 


\section{Mehanizam trokomponentnih Cu(I) kataliziranih reakcija}

Chang $i$ sur. su 2005. godine prvi put objavili saznanja o trokomponentnim $\mathrm{Cu}(\mathrm{I})$ kataliziranim reakcijama. ${ }^{6}$ Studijama koje su uslijedile, utvrdili su da se ovaj tip reakcija najvjerojatnije zbiva preko ketenimina nastalog in situ reakcijom sulfonil-azida 4 i terminalnog alkina 2. Nastali ketenimin podložan je adiciji različitih nukleofila kao što su amini, voda, alkoholi ili heterociklički spojevi pri čemu nastaju amidini $\mathbf{6}$, amidi 7, imidati 8 i heterociklički adukti
9 (shema 2). ${ }^{7}$ Međutim, ovisno o vrsti baze i temperaturi, u trokomponentnim $\mathrm{Cu}(\mathrm{I})$ kataliziranim reakcijama sulfonil-azida 4 i terminalnih alkina 2 mogu nastati i 1,4-disupstituirani-1,2,3-triazoli 5.

Vrsta produkta koji nastaje u Cu(I) kataliziranoj azid-alkinskoj cikloadiciji ovisi o tipu azida koji sudjeluje u reakciji. ${ }^{7 a}$ U reakcijama benzil- ili fenil-azida 1 s 1-alkinima 2 u prisutnosti diizopropilamina 10 dobiveni su očekivani 1,4-disupstituirani-1,2,3-triazoli 3, dok upotrebom N-sulfonil-azida pretežno nastaju amidini 11 (shema 3).

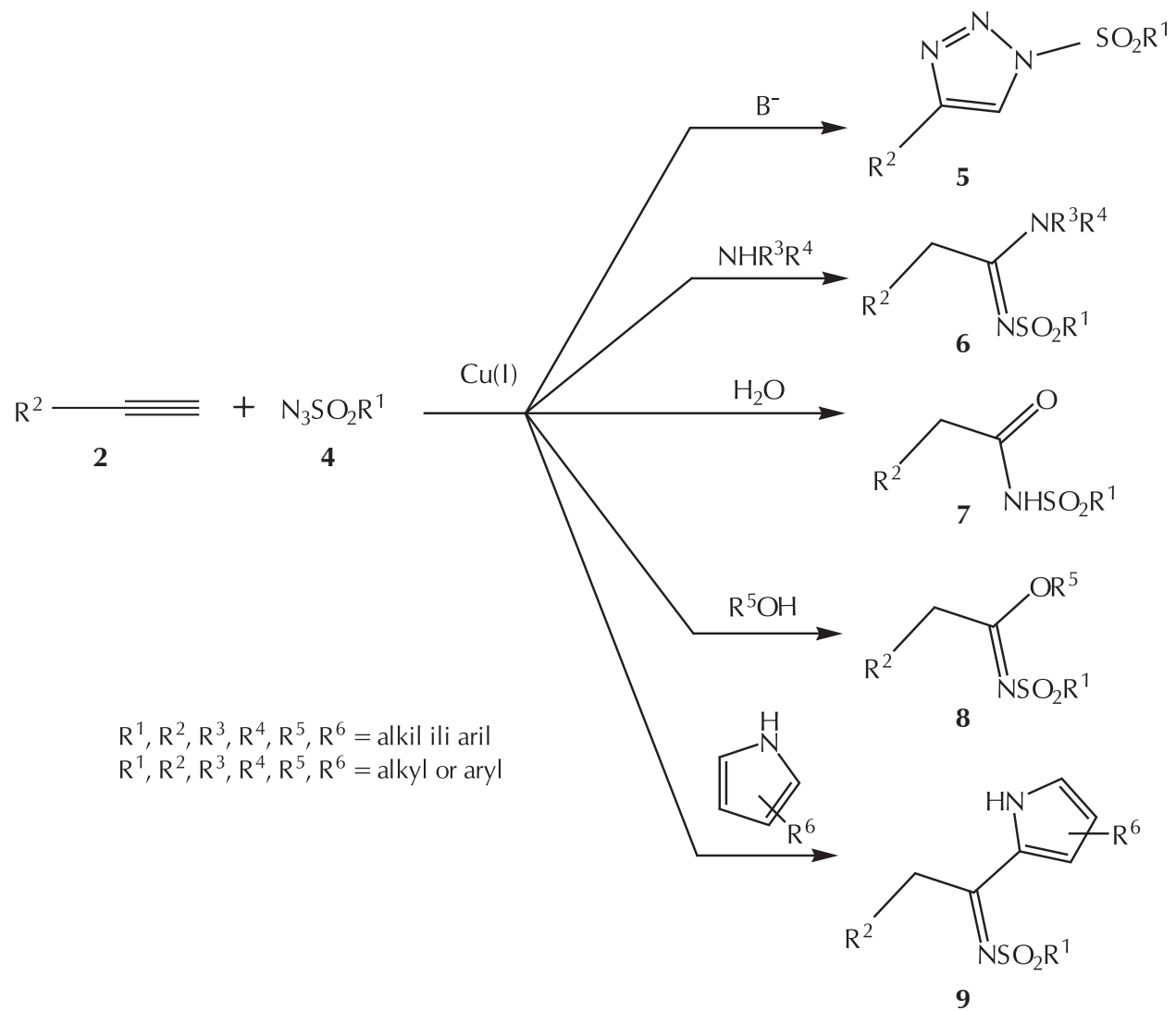

Shema 2 - Trokomponentne $\mathrm{Cu}(\mathrm{I})$ katalizirane reakcije Scheme 2 - Three-component $\mathrm{Cu}(\mathrm{I})$ catalysed reactions

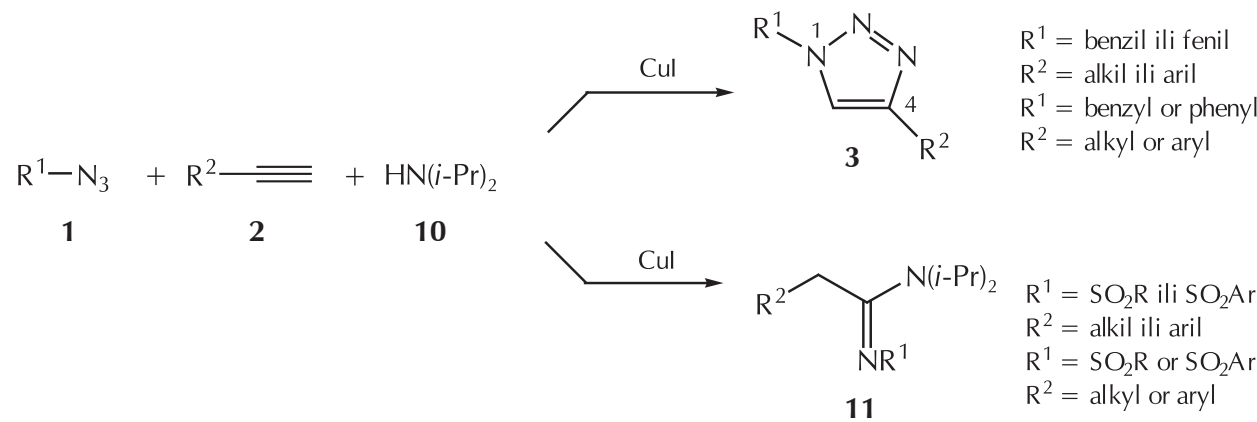

Shema 3 - Sinteza 1,4-disupstituiranih 1,2,3-triazola i N-sulfonilamidina $\mathrm{Cu}(\mathrm{I})$ kataliziranim klik-reakcijama

Scheme 3 - Synthesis of 1,4-disubstituted 1,2,3-triazoles and $\mathrm{N}$-sulfonylamidines with $\mathrm{Cu}(\mathrm{I})$ catalysed reactions 
U trokomponentnim klik-reakcijama u kojima su alkoholi upotrijebljeni kao nukleofili primijećen je isti tip selektivnosti (shema 4). Reakcijom etinilbenzena 12 s benzil-azidom 1 čak i u prisutnosti benzilnog alkohola 13 gotovo u potpunosti nastaje odgovarajući triazol 14, dok sulfonil-azid 4 $\mathrm{u}$ istim uvjetima daje imidatni produkt 15 (shema 4). ${ }^{\text {tb }} \mathrm{Za}$ dobivanje imidata u zadovoljavajućim iskorištenjima potrebno je prisustvo baze. $\mathrm{p} K_{\mathrm{a}}$ upotrijebljene baze kod reak- cije sa sulfonil-azidima ima značajan utjecaj na selektivnost reakcije. Nastajanje triazola $\mathbf{1 4}$ favorizirano je slabijim bazama, dok nastanku imidata 15 pogoduju jače baze. Temperatura također ima značajan utjecaj na ishod reakcije sa sulfonil-azidima. Na niskim temperaturama (npr. $-25{ }^{\circ} \mathrm{C}$ ) nastaje triazolni produkt 14, čak i u prisutnosti baze, ali u niskom iskorištenju. Međutim povišenjem temperature prevladava imidatni produkt 15 u većem iskorištenju. ${ }^{\text {tb }}$
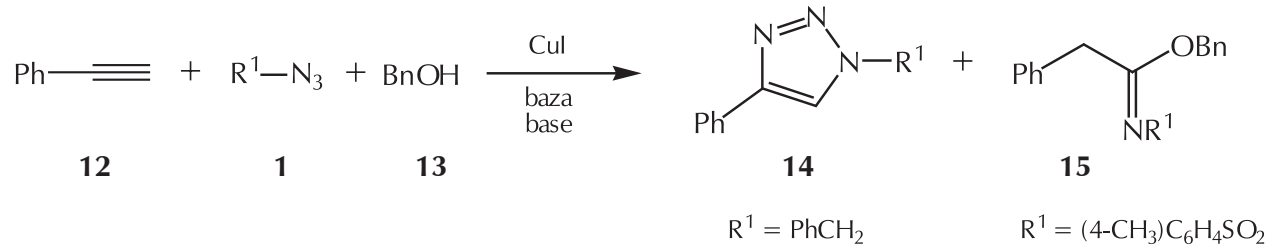

Shema 4 - Trokomponentna $\mathrm{Cu}(\mathrm{I})$ katalizirana reakcija alkina, azida i benzilnog alkohola Scheme 4 - Three-component Cu(I) catalysed reaction of alkyne, azide and benzyl alcohol

lako je nastajanje imidata entropijski povoljnije, podešavanjem reakcijskih uvjeta kojima se olakšava protoniranje bakar-triazolilnog intermedijara i snižavanjem temperature, moguće je izolirati $N$-sulfonil-1,2,3-triazole (shema 5). ${ }^{\text {a }} \mathrm{U}$ reakciji etinilbenzena $12 \mathrm{~s} p$-toluensulfonil-azidom $\left(\mathrm{Ts}_{3}\right) 16$ testiran je utjecaj temperature, vrste bakrovog katalizatora i baze te otapala na tijek reakcije. Najbolji rezultati dobiveni su na $0{ }^{\circ} \mathrm{C}$, u prisutnosti 2,6-lutidina i Cul kao katalizatora, u kloroformu, pri čemu nastaje 4-fenil-1(N-tosil)-1,2,3-triazol 17 u visokom iskorištenju od $80 \%$ (shema 5). 2,6-lutidin se pokazao kao najbolji izbor među brojnim organskim i anorganskim bazama, dok je Cul pokazao najveću katalitičku aktivnost u bezvodnim uvjetima i nepolarnom otapalu kao što je kloroform. ${ }^{\text {aa }}$

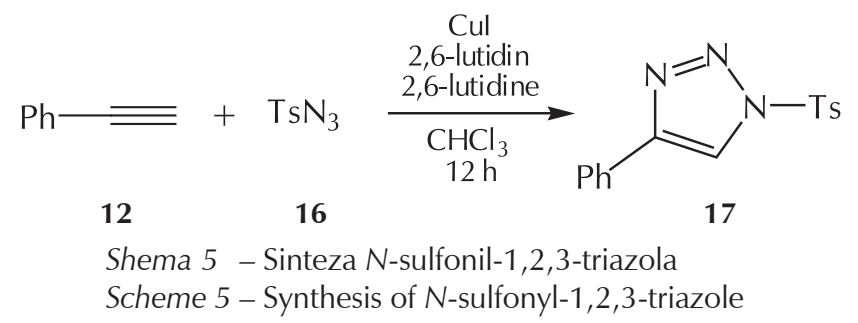

U trokomponentnim klik-reakcijama voda reagira kao treća komponenta dajući $N$-sulfonamide 7,8 dok u reakciji pirola kao nukleofila regioselektivno nastaje adukt $9 \mathrm{~s}$ novom vezom C-C u položaju C2 pirolnog prstena (shema 2). ${ }^{9}$

N-karbonil- i fosforil-azidi reagiraju na analogan način te nastaju odgovarajući amidini, imidati i amidi, mada su se sulfonil-azidi pokazali najreaktivnijima u ispitivanim reakcijama.

Na shemi 6 prikazan je najvjerojatniji mehanistički tijek $\mathrm{Cu}(\mathrm{I})$ katalizirane trokomponentne reakcije alkina, sulfonil-azida i nukleofila. lako je vjerojatno da u katalizi sudjeluje više bakrovih atoma, ${ }^{10}$ prikazane su, radi jednostavnosti, specije koje sadržavaju jedan bakrov atom.
Pretpostavljeno je da su početni stupnjevi (koraci 1, 2 i 3) u cikloadiciji terminalnog alkina i sulfonil-azida isti kao i kod bakrom katalizirane azid-alkinske 1,3-dipolarne cikloadicije koja uključuje aril- ili alkil-azide. ${ }^{11}$ Baza asocira proton s terminalnog alkina 2 i nastaje bakrov acetilid A (korak 1). Reakcijom bakrovog acetilida A sa sulfonil-azidom nastaje bakrov intermedijar B (korak 2). On ciklizira i daje šesteročlani Cu-prsten C (korak 3) i zatim pregradnjom nastaje peteročlani triazolil D (korak 4), gdje je bakar vezan na C5-položaju prstena. N-sulfoniltriazoli i N-fosforiltriazoli u ovim su uvjetima stabilni, pa se pretpostavlja da je intermedijar baš triazolilni $\mathbf{D}$, a ne triazolni oblik $\mathbf{E}$. Intermedijar D podliježe pregradnji i otvaranju prstena, što vodi do nastajanja keteniminskog intermedijara $\mathbf{F}$ i otpuštanja molekule dušika (korak 5). Energija aktivacije za otvaranje prstena je za $84 \mathrm{~kJ} \mathrm{~mol}^{-1}$ manja kod $N$-sulfoniltriazolila u odnosu na $\mathrm{N}$-alkiltriazolil. Nakon toga slijedi adicija nukleofila kao što su amini, alkoholi, voda ili heterocikli te nastaju odgovarajući amidini, imidati, amidi odnosno novi heterociklički spojevi.

Treba napomenuti da je bakrov triazolil D ključni intermedijar iz kojega, ovisno o vrsti baze i temperaturi reakcije, može protoniranjem nastati triazolni adukt $\mathbf{E}$ ili nastaje keteniminski intermedijar $\mathbf{F}$ koji reagira s nukleofilima dajući odgovarajuće produkte $\mathbf{G}$.

Mehanizam $\mathrm{Cu}(\mathrm{I})$ kataliziranih trokomponentnih reakcija sulfonil-azida, terminalnih alkina i nukleofila detaljno je opisan na temelju mehanističkih studija ${ }^{7}$ koje su pokazale da kod ovih reakcija zaista nastaje intermedijarni ketenimin $\mathbf{F}$ (strukturni derivat ketena opće formule $\mathrm{R}^{1} \mathrm{R}^{2} \mathrm{C}=\mathrm{C}=\mathrm{NR} \mathrm{R}^{3}$ ), za kojeg je poznato da reagira $\mathrm{s}$ različitim nukleofilima, elektrofilima ili radikalima. ${ }^{12}$ Uz pomoć kompeticijske studije vođene u uvjetima u kojima nastaju amidini utvrđeno je da elektron-odvlačeći supstituenti na reaktantima ubrzavaju reakciju i to manje ako se nalaze na alkinu odnosno više ako su na azidu, u stupnju koji određuje brzinu reakcije. ${ }^{7}$ Računalne metode (DFT, engl. density functional theory) također su poduprle eksperimentalne dokaze za stvaranje i raspad triazolilnog intermedijara D 


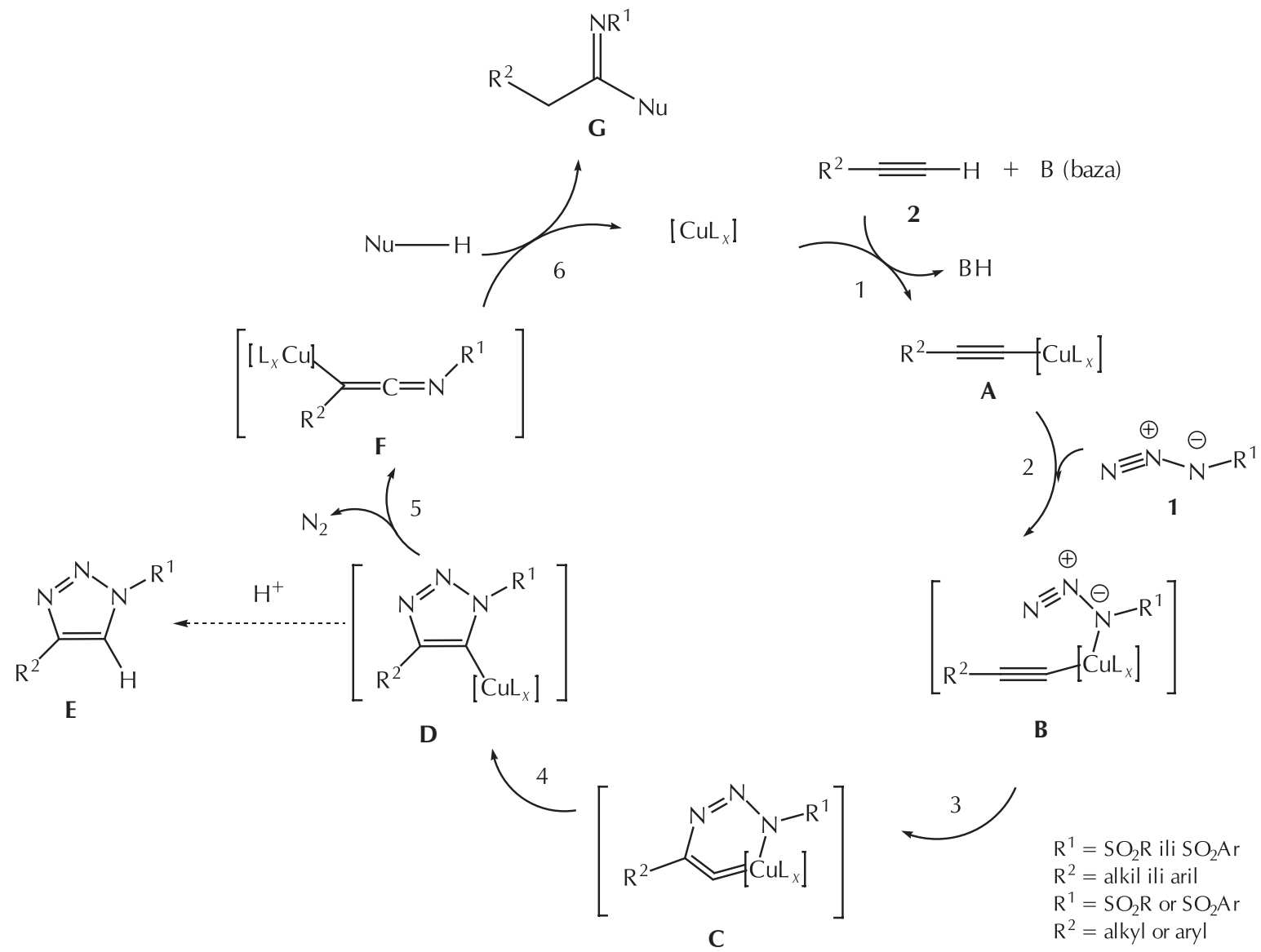

Shema 6 - Mehanizam Cu(I) katalizirane trokomponentne reakcije

Scheme 6 - Mechanistic pathway for the $\mathrm{Cu}(\mathrm{I})$ catalysed three-component reaction

(shema 6), te dokazale da zbog nižih energijskih barijera prijelaznih stanja sulfonil-azidi lakše reagiraju s bakrovim acetilidima nego alkil-azidi. ${ }^{11}$

\section{Cu katalizatori trokomponentnih klik-reakcija}

U studiji iz 2008. godine uspoređen je utjecaj različitih liganada i oksidacijskih stanja bakra na ishod trokompo- nentnih klik-reakcija. ${ }^{\text {7c }}$ Neočekivano, kod reakcija nastajanja amidina i imidata, nije uočena razlika u iskorištenjima primjenom $\mathrm{Cu}(\mathrm{II})$ katalizatora ili $\mathrm{Cu}(\mathrm{I})$ katalizatora. Kod reakcija nastajanja amida uočena su znatno veća iskorištenja uz Cu(I) katalizator.

Utjecaj liganada bakra na ishod trokomponentnih klik-reakcija ispitan je usporednim reakcijama bez liganada i uz ligande (slika 1).<smiles>CC(C)(C)CC(=O)CC(=O)Br</smiles>

L1

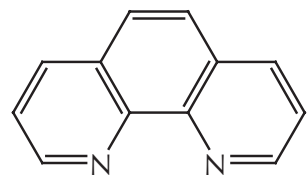

L5<smiles>CN(C)CCN(C)C</smiles>

L2<smiles>c1ccc(-c2ccccn2)nc1</smiles>

L3<smiles>COc1ccnc(-c2cc(OC)ccn2)c1</smiles>

L4<smiles>c1ccc(Cn2cc(CN(Cc3cn(Cc4ccccc4)nn3)Cc3cn(Cc4ccccc4)nn3)nn2)cc1</smiles>

Slika 1 - Testirani ligandi Cu katalizatora

Fig. 1 - Tested Cu catalyst ligands 
Utvrđeno je da svi ligandi osim tris[(1-benzil-1H-1,2,3-triazol-4-il)metil]amina (TBTA) (slika 1, L7) u određenoj mjeri inhibiraju reakcije nastajanja $\mathrm{N}$-sulfonilamidina, $\mathrm{N}$-sulfoni- lamida i N-sulfonilimidata. Reakcije uz ligand TBTA imale su nešto veća iskorištenja u slučaju $N$-sulfonilamidina i $\mathrm{N}$-sulfonilimidata (slika 2).

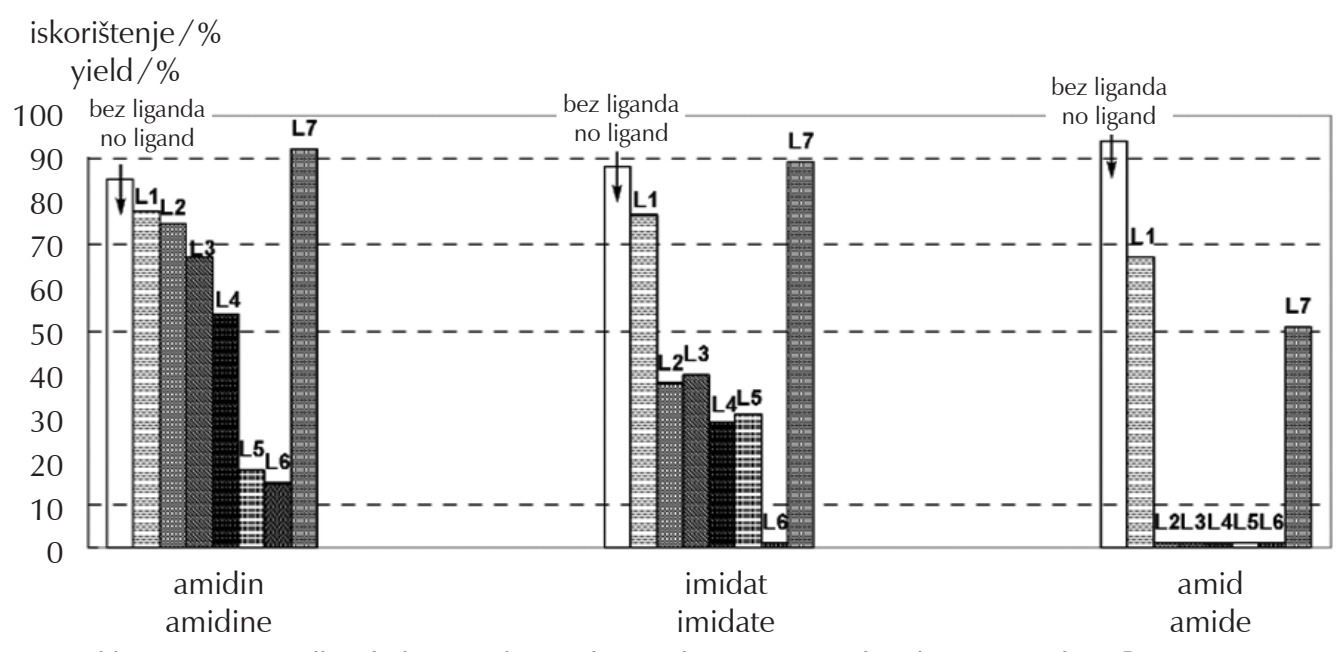

Slika 2 - Usporedba djelovanja liganada na iskorištenje Cu katalizirane reakcije ${ }^{7 c}$

Fig. 2 - Comparison of the ligands influence on the yield of the Cu catalysed reaction ${ }^{7 c}$

\section{Trokomponentne Cu(I) katalizirane reakcije}

\section{Sinteza $\mathrm{N}$-sulfonilamidina}

Amidini su spojevi široko zastupljeni u organskoj sintezi kao intermedijari i građevne jedinice kod sinteze heterocikličkih spojeva i metalnih kompleksa ${ }^{13}$ te kao farmakofori i strukturne komponente biološki aktivnih spojeva. ${ }^{14}$ Opisane su mnoge metode sinteze amidina, a najčešće se sintetiziraju iz amida, ${ }^{15}$ karboksilnih kiselina ${ }^{16}$ i nitrila. ${ }^{17}$ Sve navedene reakcije provode se u više stupnjeva, zahtijevaju bezvodne uvjete i često podrazumijevaju rad s opasnim reagensima uz složene postupke izolacije. Trokomponentna $\mathrm{Cu}(\mathrm{I})$ katalizirana sinteza sulfonilamidina $\mathbf{6}$ provodi se na sobnoj temperaturi 1 do 6 sati (shema 7), a u reakcijama sudjeluju aromatski i alifatski alkini $\mathbf{2}$ i sulfonil-azidi $\mathbf{4}$ te aromatski, primarni, sekundarni i ciklički amini $\mathbf{1 8 .}{ }^{6}$

$\mathrm{N}$-nesupstituirani $\mathrm{N}$-sulfonilamidini 20 nastaju reakcijom terminalnog alkina $\mathbf{2}$, sulfonil-azida $\mathbf{1 6}$ i amonijevog klorida ili amonijevog hidroksida, uz bazu trietilamin, katalizator Cul, u diklormetanu i pri sobnoj temperaturi (shema 8). U reakcijama s amonijevim kloridom ili amonijevim hidroksidom i $p$-toluensulfonil-azidom $\mathbf{1 6}$ sudjeluju aromatski ili alifatski terminalni alkini 2 . Voda u amonijevom hidroksidu ne utječe na tijek reakcije te su iskorištenja reakcija nešto bolja uz upotrebu amonijeva hidroksida umjesto amonijeva klorida (shema 8$).{ }^{18}$

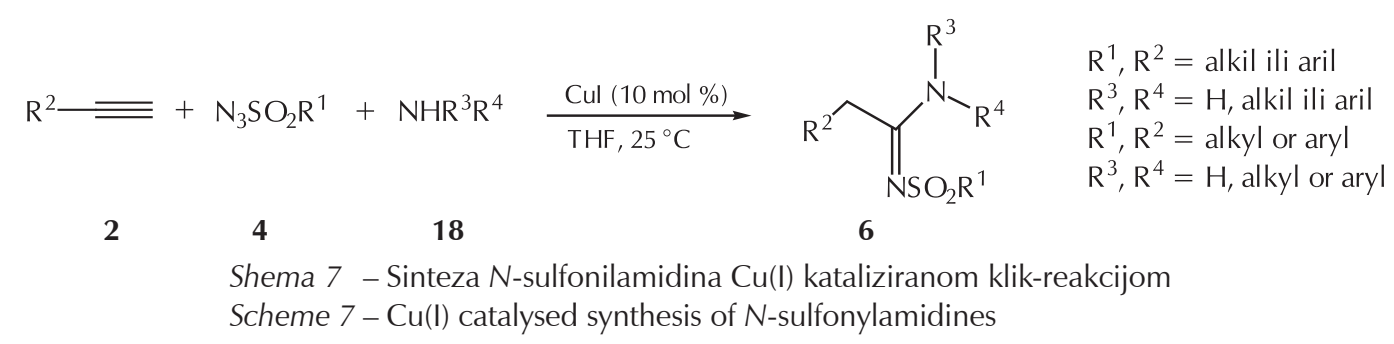

$$
\begin{aligned}
& \mathrm{R}^{2}=+\mathrm{N}_{3} \mathrm{Ts}+\mathrm{NH}_{4} \mathrm{X} \underset{\mathrm{CH}_{2} \mathrm{Cl}_{2}, 25^{\circ} \mathrm{C}}{\stackrel{\mathrm{Cul}(10 \mathrm{~mol} \%)}{\mathrm{Et}_{3} \mathrm{~N}}} \\
& \begin{array}{llll}
2 & 16 & 19 & 20
\end{array} \\
& \mathrm{X}=\mathrm{Cl}, \mathrm{OH} \\
& \mathrm{R}^{2}=\text { alkil ili aril } \\
& \mathrm{R}^{2}=\text { alkyl or aryl }
\end{aligned}
$$

Shema 8 - Sinteza $N$-nesupstituiranih $N$-sulfonilamidina $\mathrm{Cu}(\mathrm{I})$ kataliziranom klik-reakcijom uz amonijev klorid ili amonijev hidroksid

Scheme $8-\mathrm{Cu}(\mathrm{I})$ catalysed synthesis of $\mathrm{N}$-nonsubstitued $\mathrm{N}$-sulfonylamidines with ammonium chloride or ammonium hydroxide 
Trokomponentna reakcija s amonijevim kloridom 19 primijenjena je kod sinteze $2 \mathrm{H}$-1,2,4-benzotiadizin-1,1-dioksida 23 koji je dobiven intramolekularnim $\mathrm{N}$-ariliranjem $\mathrm{N}$-nesupstituiranog $\mathrm{N}$-sulfonilamidina 22 (shema 9).

Trokomponentnom $\mathrm{Cu}(\mathrm{I})$ kataliziranom reakcijom $p$-toluensulfonil-azida 16, etinilbenzena 12 i soli optički aktivnog estera 24, uz bazu trietilamin nastaje optički aktivan $\mathrm{N}$-sulfonilamidin $\mathbf{2 5}$ u visokom iskorištenju bez naznaka racemizacije (shema 10$){ }^{6}$

Mandal i sur. sintetizirali su glikozidne $N$-sulfonilamidine $\mathbf{2 7}$ trokompentnom reakcijom glikozidnog alkina $\mathbf{2 6}$, sulfonil-azida 4 i amina 18 (shema 11). ${ }^{19}$ Uvjeti reakcije ispitani su s različitim alkinima, azidima i aminima. Najbolja iskorištenja dobivena su u reakcijama uz Cul kao katalizator i u smjesi otapala $\mathrm{THF} / \mathrm{H}_{2} \mathrm{O} 4: 1$.

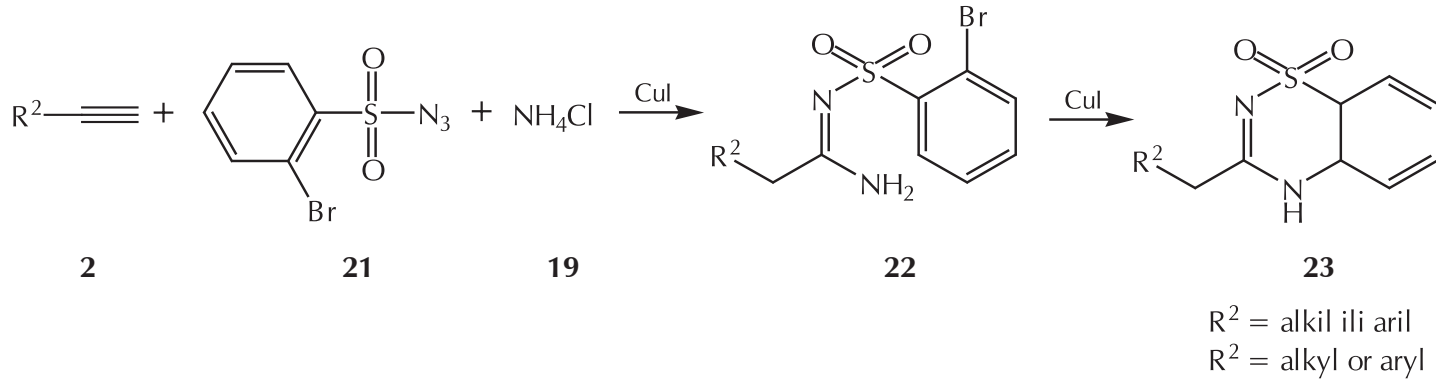

Shema 9 - Sinteza 2H-1,2,4-benzotiadizin-1,1-dioksida Scheme 9 - Synthesis of $2 \mathrm{H}$-1,2,4-benzothiadizine-1,1-dioxide<smiles>COC(=O)[C@@H](N)C[Pb]NCCCCCC(C)(C)C(F)(F)F</smiles>
12
16<smiles>COC(=O)[C@H](Cc1ccccc1)NC(=[NH2+])Cc1ccccc1</smiles>

25

Shema 10 - Sinteza optički aktivnog N-sulfonilamidina

Scheme 10 - Synthesis of optically active $\mathrm{N}$-sulfonylamidine

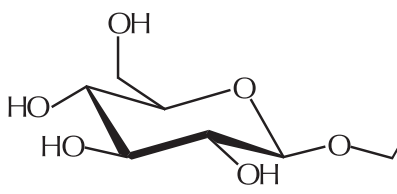

26

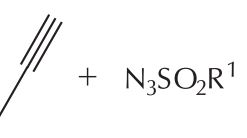

4

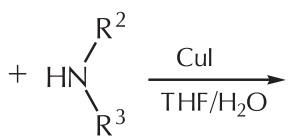

18

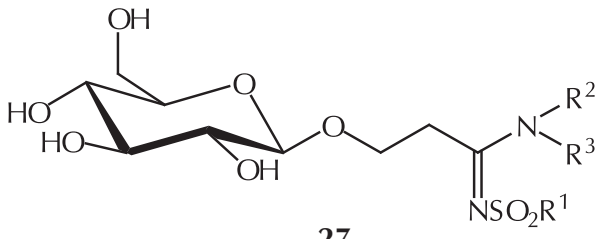

27

$\mathrm{R}^{1}=$ metil ili benzil

$\mathrm{R}^{2}, \mathrm{R}^{3}=\mathrm{H}$, alkil ili benzil

$\mathrm{R}^{1}=$ methyl or benzyl

$\mathrm{R}^{2}, \mathrm{R}^{3}=\mathrm{H}$, alkyl or benzyl

Shema 11 - Sinteza glikozidnih N-sulfonilamidina

Scheme 11 - Synthesis of glycosylated N-sulfonylamidines 
U trokomponentnim reakcijama upotrebljavaju se tercijarni amini kao dodatne baze, no Li i sur. opisali su $\mathrm{Cu}(\mathrm{l})$ kataliziranu reakciju dobivanja $\mathrm{N}$-sulfonilformamidina 29 reakcijom aromatskih sulfonil-azida $\mathbf{4}$ s tercijarnim aminima $\mathbf{2 8}$ uz tetraklorugljik koji ima dvojnu ulogu reagensa i otapala. Iskorištenja reakcija su visoka bez obzira na elektronsku prirodu supstituenta na aromatskim sulfonil-azidima, a reakcija se odvija i s cikličkim tercijarnim aminima (shema 12). ${ }^{20}$<smiles></smiles>

4<smiles>[R]OS(=O)/N=C\N([R])[R]</smiles>

29
$\mathrm{R}^{1}=$ alkil ili aril

$\mathrm{R}^{2}, \mathrm{R}^{3}, \mathrm{R}^{4}=\mathrm{H}$, alkil ili aril

$\mathrm{R}^{1}=$ alkyl or aryl

$\mathrm{R}^{2}, \mathrm{R}^{3}, \mathrm{R}^{4}=\mathrm{H}$, alkyl or aryl

Shema 12 - Sinteza N-sulfonilformamidina

Scheme 12 - Synthesis of $\mathrm{N}$-sulfonylformamidines

Pretpostavljeni mehanizam reakcije prikazan je na shemi 13. Inicijalno u reakciji nastaje amonijeva sol A iz koje anion $\mathrm{CCl}_{3}^{-}$uzima proton, pri čemu nastaje kloroform, a oslobođeni kloridni ion nukleofilnom adicijom na međuprodukt B daje 1-klor-N,N-dietiletanamin 31. Uz pomoć još jedne molekule trietilamina eliminacijom se uklanja $\mathrm{HCl}$ i nastaje enamin 32. Mehanizmom 1,3-dipolarne cikloadicije između nastalog enamina i sulfonil-azida na- staje N-sulfonilformamidin $\mathbf{3 3 .}$

Yavari i sur. opisali su trokomponentnu reakciju dobivanja $\mathrm{N}$-sulfonilamidina 6, u kojoj uz tercijarni amin $\mathbf{3 4}$ sudjeluju sulfonil-azidi 4, terminalni alkini 2 i Cul katalizator (shema 14). ${ }^{21}$ Reakcija se odvija na povišenoj temperaturi, a aromatski alkini daju bolja iskorištenja od alifatskih.

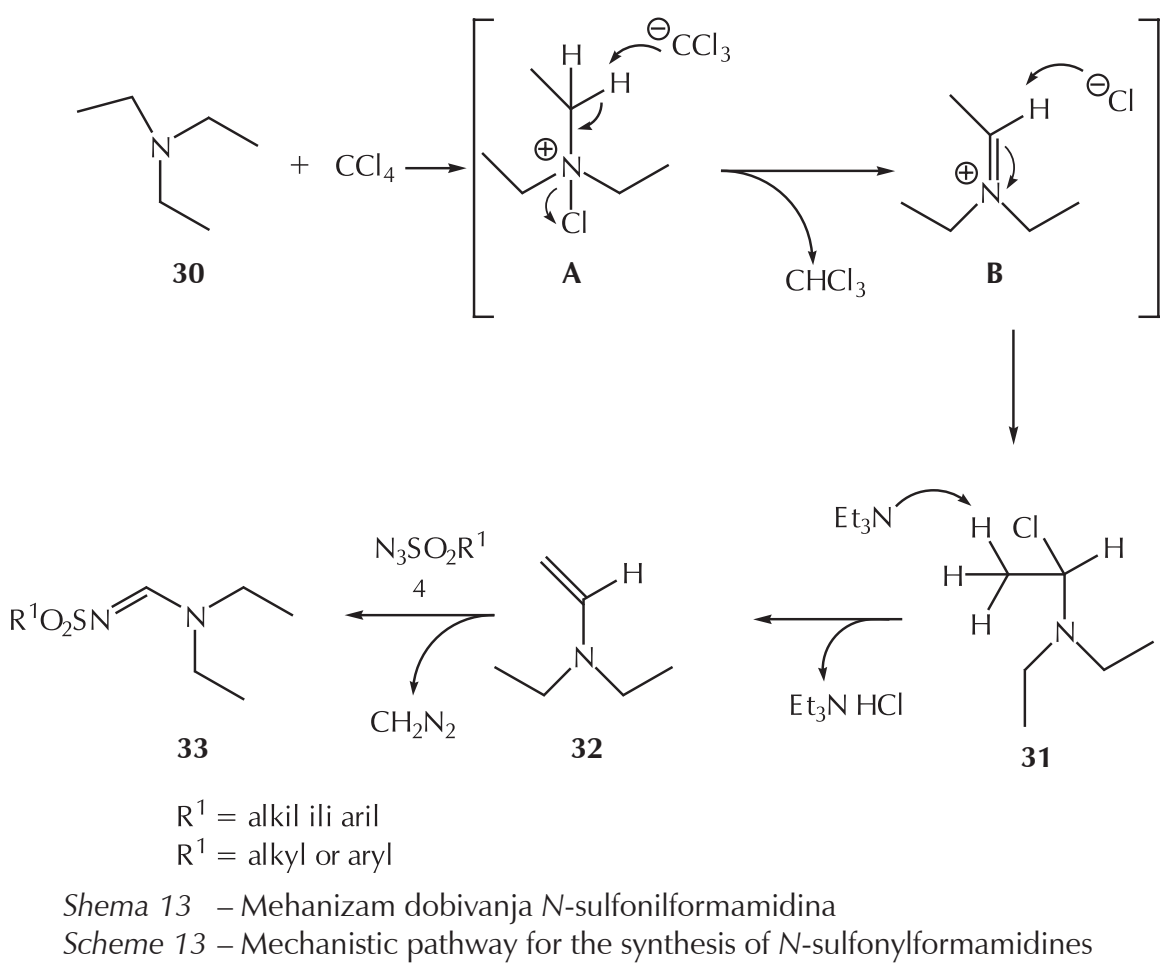

$\mathrm{R}^{2}=+\mathrm{N}_{3} \mathrm{SO}_{2} \mathrm{R}^{1}+\mathrm{NR}^{3} \mathrm{R}^{4} \mathrm{R}^{5} \frac{\mathrm{Cul}(10 \mathrm{~mol} \%)}{\mathrm{THF}, 60^{\circ} \mathrm{C}}$

2<smiles>[R]CC(=N[R])N([R])[R]</smiles>

6

$$
\begin{aligned}
& R^{1}=\text { alkil ili aril } \\
& R^{2}=\text { aril } \\
& R^{3}, R^{4}, R^{5}=\text { metil, etil ili izopropil } \\
& R^{1}=\text { alkyl or aryl } \\
& R^{2}=\text { aryl } \\
& R^{3}, R^{4}, R^{5}=\text { methyl, ethyl or isopropyl }
\end{aligned}
$$

Shema 14 - Sinteza $N$-sulfonilamidina reakcijom alkina, sulfonil-azida i tercijarnih amina Scheme 14 - Synthesis of $\mathrm{N}$-sulfonylamidines, with reaction of alkynes, sulfonyl azides and tertiary amines 
Pretpostavljeni mehanizam te reakcije prikazan je na shemi 15. Prvi dio reakcije slijedi prethodno prikazani mehanizam trokomponentne $\mathrm{Cu}(\mathrm{I})$-katalizirane reakcije (shema 2), gdje cikloadicijom bakrovog acetilida i sulfo- nil-azida 4 nastaje triazolil A, koji se pregrađuje u ketenimin B. Trialkilamin reagira $\mathrm{s}$ nastalim keteniminom $\mathbf{B}$ dajući zwitterion $\mathbf{C}$ koji vjerojatno utjecajem vlage daje sol D. Dealkiliranjem soli D uz trialkilamin nastaje amidin 35 .

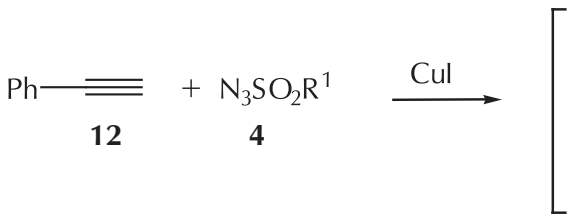<smiles>O=[SH](=O)n1nnc(-c2ccccc2)c1Cl</smiles>

A<smiles>O=[N+]([O-])C=C=C(Cl)c1ccccc1</smiles>
$\downarrow \mathrm{R}_{3} \mathrm{~N}$<smiles>[R]N([R])C(Cc1ccccc1)=[N+]([R])[O-]</smiles>

35

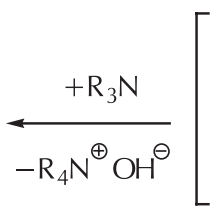

$\mathrm{R}=$ alkil $\mathrm{R}^{1}=$ aril

$\mathrm{R}=$ alkyl $\mathrm{R}^{1}=$ aryl<smiles>[R19]C(Cc1ccccc1)=[N+]([R3])[R]O</smiles>

D<smiles>[R]OS(=O)(=O)C([R9])Cc1ccccc1</smiles>

C

Shema 15 - Mehanizam dobivanja $N$-sulfonilamidina reakcijom alkina, sulfonil-azida i tercijarnih amina

Scheme 15 - Mechanistic pathway for the synthesis of $N$-sulfonylamidines in the reaction of alkynes, sulfonyl azides and tertiary amines

\section{Sinteza $N$-fosforilamidina}

$\cup$ trokomponentnim reakcijama nastajanja $\mathrm{N}$-fosforilamidina 37, s terminalnim alkinom 2 i aminom 10 reagira fosforil-azid 36 (shema 16). ${ }^{22}$
Pretpostavljen je identični mehanizam reakcije kao i kod sulfonil-azida. Cikloadicijom azida 36 i alkina 2 nastaje triazolil koji se oslobađanjem dušika pregrađuje u ketenimin, a on podliježe nukleofilnoj adiciji amina, pri čemu nastaje $N$-fosforilamidin 37 . $U$ reakcijama dobivanja $N$-fo-

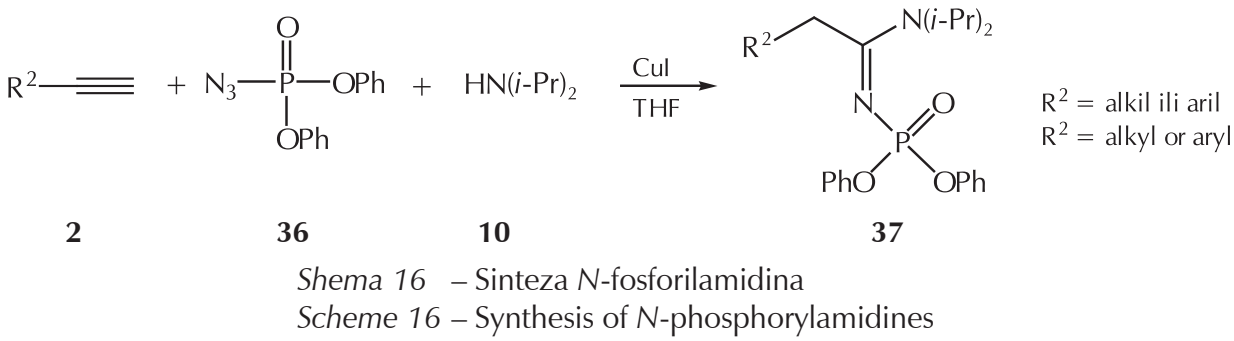


sforilamidina upotrijebljeni su terminalni alkini s različitim alifatskim, aromatskim, heterocikličkim i sterički zaklanjajućim supstituentima, a produkti nastaju u vrlo dobrim odnosno odličnim iskorištenjima. Nije uočen utjecaj sup- stituenta terminalnog alkina na ishod reakcije, a u reakcijama jednako uspješno sudjeluju alifatski, ciklički i optički aktivni amini. Utjecaj supstituenata na fosforil-azidu 38 na iskorištenja reakcija prikazan je na shemi 17.

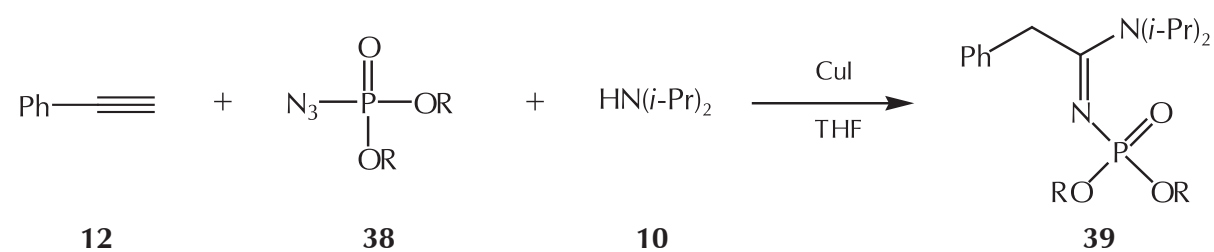<smiles>CCOP(N)(=O)OCC</smiles>

$13 \%$<smiles>CC1(C)COP(N)(=O)OC1</smiles>

$26 \%$<smiles>COCCOP(N)(=O)OC</smiles>

$59 \%$<smiles>NS(=O)(O)(O)O</smiles>

$90 \%$<smiles></smiles>

$93 \%$

Shema 17 - Reaktivnost fosforil-azida u trokomponentnim Cu(I) kataliziranim reakcijama22 Scheme 17 - Reactivity of phoshporyl azides in three-component $\mathrm{Cu}(\mathrm{I})$ catalysed reactions $^{22}$

Trokomponentnom $\mathrm{Cu}(\mathrm{I})$ kataliziranom reakcijom sulfonil-azida ili fosforil-azida $\mathbf{1}$, amina $\mathbf{1 8}$ i inamida kao alkina 40, nastaju $\alpha$-amino- $N$-sulfonilamidini tj. $\alpha$-amino- $N$-fosforilamidini 41 (shema 18). ${ }^{23} \mathrm{U}$ reakciji sudjeluju aromat- ski ili alkil-azidi te primarni ili sekundarni amini. Chang i sur. testirali su niz $\mathrm{Cu}$ katalizatora i otapala, a najbolja iskorištenja dobivena su s katalizatorima $\mathrm{Cul} \mathrm{i} \mathrm{CuCN}$ u kloroformu.<smiles>[R]OP(=O)(O[R20])O[R]</smiles><smiles>[R]N=C(CN([R])[R])N([R])[Y]</smiles>

41

Shema 18 - Sinteza $\alpha$-amino- $N$-sulfonilamidina i $\alpha$-amino- $N$-fosforilamidina

Scheme 18 - Synthesis of $\alpha$-amino $N$-sulfonylamidines and $\alpha$-amino $N$-phosphorylamidines 


\section{Sinteza $\mathrm{N}$-sulfonilimidata}

Imidati (karboksiimidati, imido esteri) su poznati farmakofori i sintetske građevne jedinice. ${ }^{24}$ Imidati se najčešće sintetiziraju Pinnerovom reakcijom nitrila i alkohola u kiselim uvjetima. ${ }^{17 a, b} \mathrm{~N}$-sulfonilimidati 8 nastaju trokomponentnom $\mathrm{Cu}(\mathrm{I})$ kataliziranom reakcijom sulfonil-azida 4, terminalnog alkina 2 i alkohola 42, uz bazu trietilamin u kloroformu (shema 19). Bez dodatka baze ne dolazi do reakcije. U reakciji sudjeluju primarni i sekundarni alkoholi, supstituirani fenoli i dioli (daju 1,3-bisimidatne produkte) te alifatski i aromatski terminalni alkini i sulfonil-azidi. ${ }^{25}$

Metilni N-sulfonilimidat 43 reakcijom s cikličkim aminom 44, uz NaCN kao katalizator, daje $\mathrm{N}$-sulfonilamidin 45 (shema 20). ${ }^{26}$ Reakcija se odvija u metanolu pri $50{ }^{\circ} \mathrm{C}$.

Trokomponentnom $\mathrm{Cu}(\mathrm{I})$ kataliziranom reakcijom inamida 46, $p$-toluensulfonil-azida 16 i metanola dobiva se $\alpha$-amino-N-sulfonilimidat 47 (shema 21)
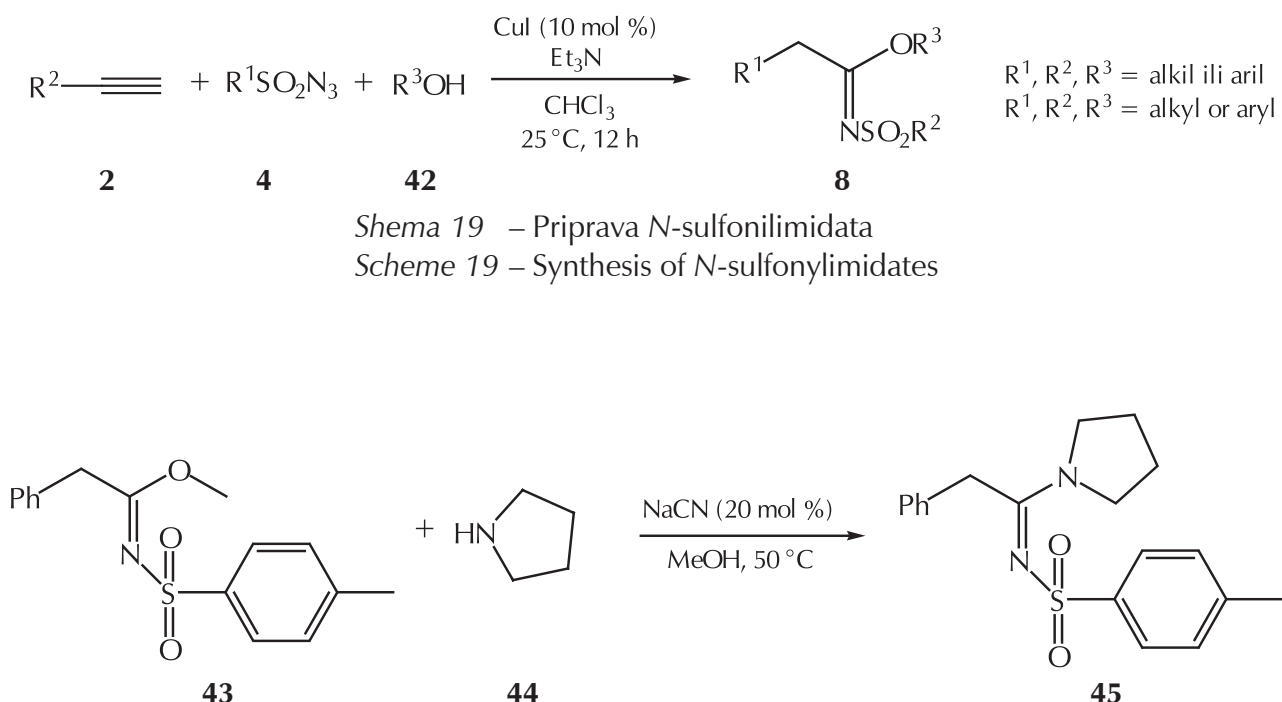

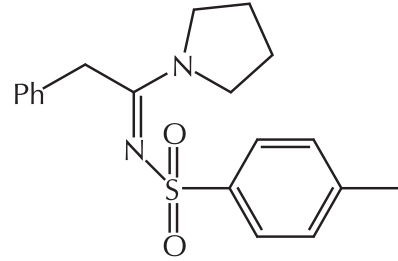

45

Shema 20 - Sinteza N-sulfonilamidina iz N-sulfonilimidata

Scheme 20 - Synthesis of $\mathrm{N}$-sulfonylamidines from $\mathrm{N}$-sulfonylimidates

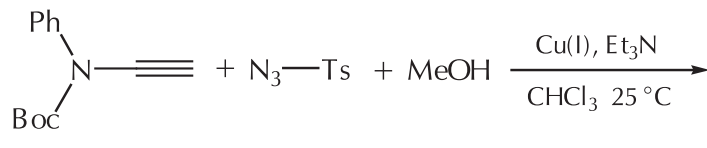

46

16<smiles>[3H]N=C(CN(C(=O)OC(C)(C)C)c1ccccc1)OC</smiles>

47

Shema 21 - Sinteza $\alpha$-amino-N-sulfonilimidata

Scheme 21 - Synthesis of $\alpha$-amino $N$-sulfonylimidates

\section{Sinteza $\mathrm{N}$-sulfonilamida}

Amidna skupina jedna je od ključnih struktura u kemiji i biologiji. ${ }^{26} \mathrm{~N}$-sulfonilamidi 7 nastaju trokomponentnom $\mathrm{Cu}(\mathrm{I})$ kataliziranom reakcijom sulfonil-azida 4, 1-alkina
2 i vode (shema 22). ${ }^{8 a, b, d}$ Utvrđeno je da do reakcije ne dolazi bez dodatka baze, a najbolja iskorištenja dobivena su s trietilaminom. $U$ reakciji sudjeluju aromatski i alifatski alkini i sulfonil-azidi, dajući dobra iskorištenja neovisno o različitim elektronskim i steričkim svojstvima supstituenata.

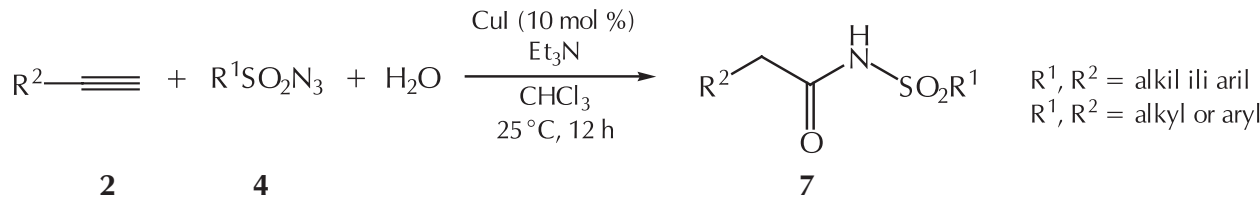

Shema 22 - Sinteza N-sulfonilamida

Scheme 22 - Synthesis of $\mathrm{N}$-sulfonylamides 


\section{Stvaranje veze ugljik-ugljik}

Sudjelovanjem pirola $\mathbf{4 8}$ kao ugljikovog nukleofila uz terminalni alkin $\mathbf{2}$ i $p$-toluensulfonil-azid $\mathbf{1 6}$ u trokomponentnim Cu kataliziranim reakcijama dolazi do stvaranje veze C-C i supstitucije pirola 49 u položaju C2. Nije uočen utjecaj elektronske prirode $\mathrm{N}$-supstituenata kao ni utjecaj supstituenata na ostalim položajima pirola. $U$ reakciji uz p-toluensulfonil-azid $\mathbf{1 6}$ jednako uspješno sudjeluju i alifatski i aromatski alkini 2. Kada su uz terminalni alkin 2 i p-toluensulfonil-azid $\mathbf{1 6}$ u reakcijama upotrebljavani drugi heterocikli poput furana, tiofena ili imidazola, ne nastaju odgovarajući produkti, što navodi na zaključak da se pirolni dušik koordinira na bakar u keteniminskom intermedijaru A i tako omogućava stvaranje produkta (shema 23). ${ }^{9}$

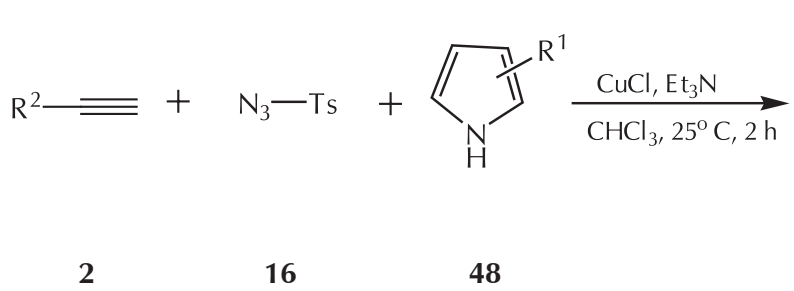

[<smiles>[R]C(=C=N[Tl])Cn1ccc([R1])c1</smiles>

A

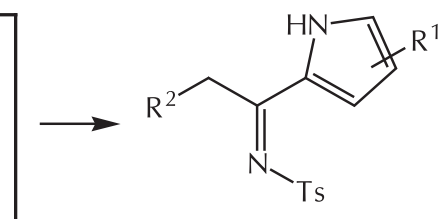

49

$$
\begin{aligned}
& \mathrm{R}^{1}=\text { alkil ili aril } \\
& \mathrm{R}^{2}=\text { metil, etil ili pirol } \\
& \mathrm{R}^{1}=\text { alkyl or aryl } \\
& \mathrm{R}^{2}=\text { methyl, ethyl or pyrrole }
\end{aligned}
$$

Shema 23 - Sinteza 2-supstituiranih pirola trokomponentnom Cu kataliziranom reakcijom Scheme 23 - Synthesis of 2-substituted pyrrole with three-component $\mathrm{Cu}$ catalysed reaction

U trokomponentnim Cu kataliziranim reakcijama uz sulfonil-azid $\mathbf{4}$ i alkin $\mathbf{2}$ sudjeluje i indol $\mathbf{5 0}$ (shema 24). Kod tih reakcija dolazi do supstitucije u položaju C3 indolnog prstena. Za uspješnu reakciju presudno je da se u položaju C2 indola nalazi supstituent koji nije elektronodvlačeće prirode, jer u protivnom ne dolazi do trokomponentne re- akcije. Nije uočen utjecaj $N$-supstituenta na indolu $\mathbf{5 0}$ kao ni utjecaj supstituenata na terminalnom alkinu 2 i sulfonil-azidu 4. Kada se reakcija odvija uz prisustvo kisika, dolazi do oksidacije i nastanka produkta 51. Produkt 52, koji nastaje $u$ inertnoj atmosferi argona, moguće je oksidirati u produkt 51, ali samo uz prisutnost Cu katalizatora. ${ }^{27}$

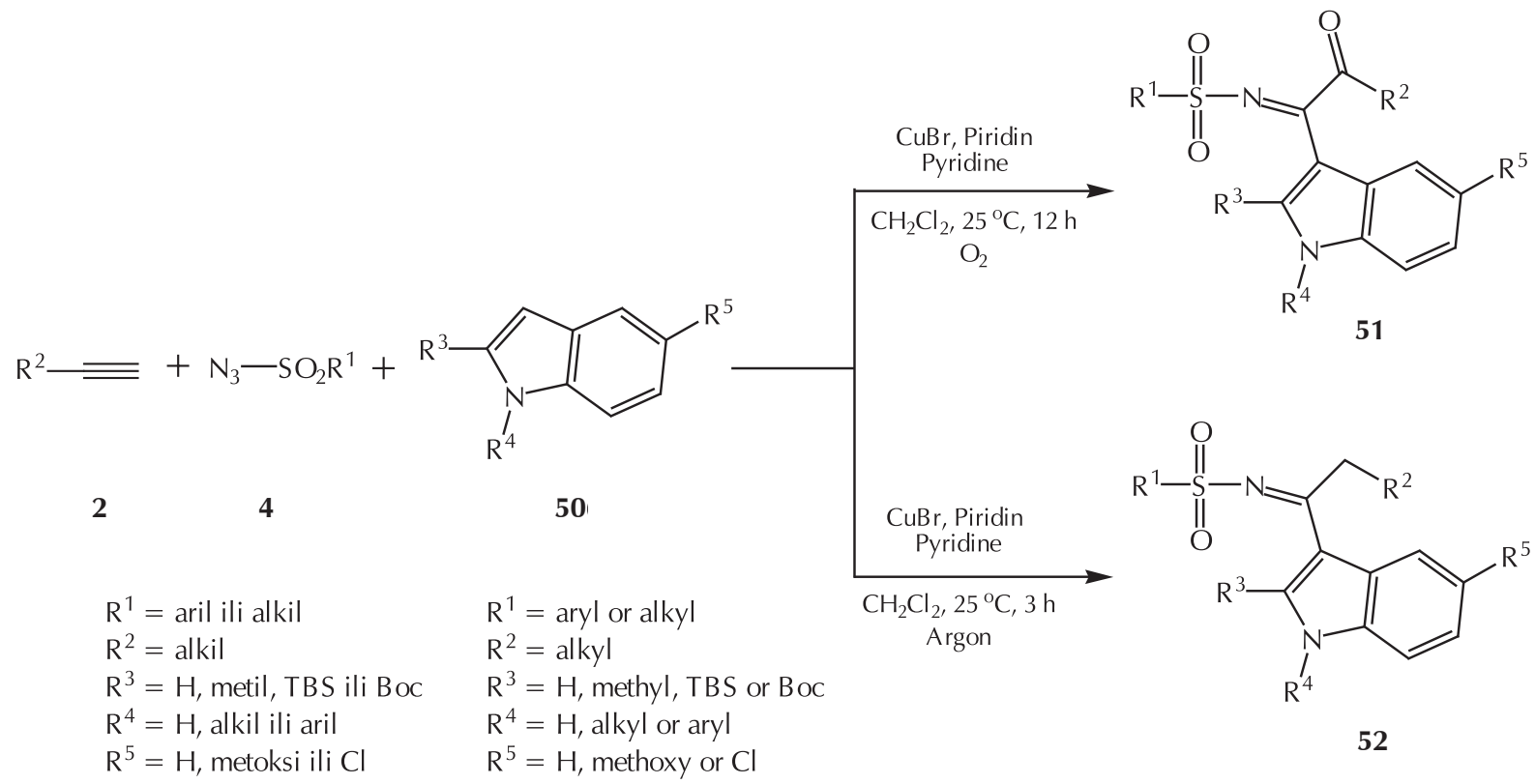

Shema 24 - Sinteza 3-supstituiranih indola trokomponentnom Cu kataliziranom reakcijom Scheme 24 - Synthesis of 3-substituted indoles with three-component Cu catalysed reaction 
Benzensulfonilna skupina se upotrebljava kao jedna od stabilnijih zaštitnih skupina dušika koji je vezan na alifatski lanac ili je dio heterocikličkog sustava. Skupina se uvodi reakcijom odgovarajućeg benzensulfonil-klorida i HN-spoja uz bazu kao što je piridin ili trietilamin. Postoji velik broj poznatih metoda uklanjanja sulfonilne skupine: natrijevim naftalenidom u 1,2-dimetoksietanu (DME), ${ }^{28}$ magnezijem $\mathrm{u}$ metanolu, ${ }^{29}$ tetrabutilamonijevim fluoridom (TBAF) u THF-u. ${ }^{30}$ Chang $i$ sur. objavili su radove u kojima opisuju uspješno uklanjanje $p$-toluensulfonilne skupine kod $\mathrm{N}$-sulfonilamida $\mathbf{5 3}{ }^{8 \mathrm{a}}$ i $\mathrm{N}$-sulfonilamidina $\mathbf{5 5}^{25} \mathrm{~s}$ natrijevim naftalenidom u DME-u (shema 25).<smiles>Cc1ccc(S(=O)(=O)NC(=O)Cc2ccccc2)cc1</smiles>

53

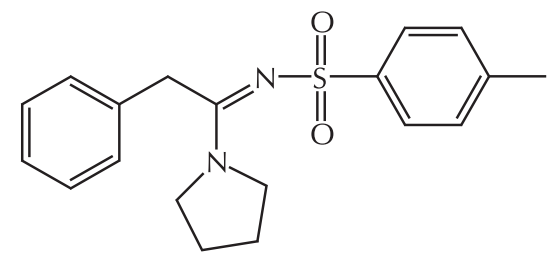

55<smiles>NC(=O)Cc1ccccc1</smiles>

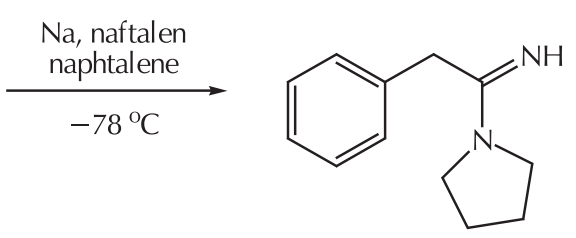

56
$(90 \%)$

Shema 25 - Uklanjanje p-toluensulfonilne skupine s natrijevim naftalenidom kod N-sulfonilamida i $N$-sulfonilamidina

Scheme 25 - Removal of the $p$-toluenesulfonyl group in $N$-sulfonylamides and $N$-sulfonylamidines with sodium naphthalenide

\section{Zaključak}

Bakrom katalizirana cikloadicija 1-alkina i azida kojom nastaju 1,4-disupstituirani-1,2,3-triazoli, najpoznatija je klik-reakcija sa širokim rasponom primjene. Upotrebom sulfonil- odnosno fosforil-azida i terminalnih alkina, ovisno o uvjetima i trećoj nukleofilnoj komponenti koja sudjeluje u reakciji, nastaju odgovarajući amidi, imidati, amidini ili supstituirani heterocikli. Mehanizam reakcije podrazumijeva otvaranje bakar-triazolnog intermedijara i nastanak ketenimina podložnog reakcijama nukleofilne adicije. Ove svestrane trokomponentne reakcije omogućavaju lagani pristup nizu produkata pogodnih za biološka ispitivanja, čija priprava inače podrazumijeva višestupnjevitu i složenu sintezu.

\section{Popis kratica \\ List of abbreviations}

$$
\begin{aligned}
\text { BOC } & \text { - tert-butiloksikarbonil } \\
& - \text { tert-butyloxycarbonyl } \\
\text { CuAAC } & \text { - bakrom(I) katalizirana azid-alkinska cikloadicija } \\
& \text { - copper (I) catalysed azide-alkyne cycloaddition } \\
\text { DFT } & \text { - teorija funkcionalne gustoće } \\
& \text { - density functional theory } \\
\text { DME } & -1,2 \text {-dimetoksietan } \\
& -1,2 \text {-dimethoxyethane } \\
\mathrm{Et}_{3} \mathrm{~N} & - \text { trietilamin } \\
& \text { - triethylamine }
\end{aligned}
$$

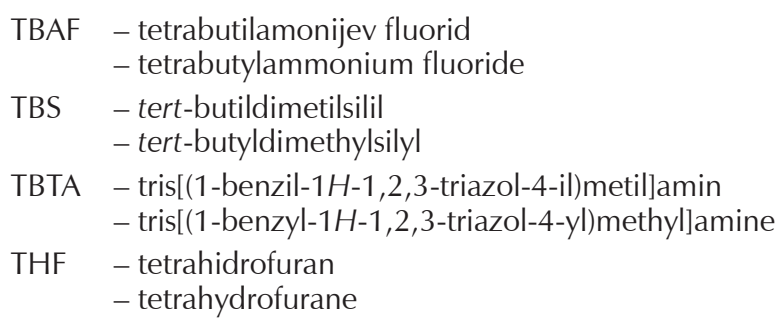

\section{Literatura \\ References}

1. H. C. Kolb, M. G. Finn, K. B. Sharpless, Click chemistry: Diverse chemical function from a few good reactions, Angew. Chem. Int. Ed. 40 (2001) 2004-2021, doi: http://dx.doi. org/10.1002/1521-3773(20010601)40:11<2004::AIDANIE2004>3.3.CO;2-X.

2. a) V. V. Rostovtsev, L. G. Green, V. V. Fokin, K. B. Sharpless, A stepwise Huisgen cycloaddition process: Copper(I)-catalyzed regioselective ligation of azides and terminal alkynes, Angew. Chem. Int. Ed. 41 (2002) 2596-2599, doi: http://dx.doi.org/10.1002/15213773(20020715)41:14<2596: :AID-ANIE2596>3.0. CO;2-4; b) C. W. Tornre, C. Christensen, M. Meldal, Peptidotriazoles on solid phase: $[1,2,3]$-Triazoles by regiospecific copper(I)-catalyzed 1,3-dipolar cycloadditions of terminal alkynes to azides, J. Org. Chem. 67 (2002) 3057-3064, doi: http://dx.doi.org/10.1021/jo011148j.

3. R. Huisgen, 1,3-Dipolar cycloaddition chemistry - introduction, survey, mechanism u A. Padwa (ur.), 1,3-Dipolar Cy- 
cloaddition Chemistry Vol 1, John Wiley \& sons, New York, 1984, str. 1-176.

4. a) W. G. Lewis, L. G. Green, F. Grynszpan, Z. Radić, P. R. Carlier, P. Taylor, M. G. Finn, K. B. Sharpless, Click chemistry in situ: Acetylcholinesterase as a reaction vessel for the selective assembly of a femtomolar inhibitor from an array of building blocks, Angew. Chem. Int. Ed. 41 (2002) 1053-1057, doi: http://dx.doi.org/10.1002/15213773(20020315)41:6\%3C1053::AID-ANIE1053\%3E3.0. CO;2-4; b) Q. Wang, T. R. Chan, R. Hilgraf, V. V. Fokin, K. B. Sharpless, M. G. Finn, Bioconjugation by copper(I)-catalyzed azide-alkyne [3 + 2] cycloaddition, J. Am. Chem. Soc. 125 (2003) 3192-3193, doi: http://dx.doi.org/10.1021/ ja021381e; c) A. D. Moorhouse, A. M. Santos, M. Gunaratnam, M. Moore, S. Neidle, J. E. Moses, Stabilization of G-quadruplex DNA by highly selective ligands via click chemistry, J. Am. Chem. Soc. 128 (2006) 15972-15973, doi: http://dx.doi.org/10.1021/ja021381e; d) F. Amblard, J. H. Cho i R. F. Schinazi, Cu(I)-catalyzed Huisgen azide-alkyne 1,3-dipolar cycloaddition reaction in nucleoside, nucleotide, and oligonucleotide chemistry, Chem. Rev. 109 (2009) 4207-4220, doi: http://dx.doi.org/10.1021/cr9001462; e) A. H. El-Sagheer, T. Brown, Click chemistry with DNA, Chem. Soc. Rev. 39 (2010) 1388-1405, doi: http://dx.doi. org/10.1039/b901971p; f) P. Thirumurugan, D. Matosiuk, K. Jozwiak, Click chemistry for drug development and diverse chemical-biology applications, Chem. Rev. 113 (2013) 4905-4979, doi: http://dx.doi.org/10.1021/cr200409f.

5. a) P. Wu, A. K. Feldman, A. K. Nugent, C. J. Hawker, A. Scheel, B. Voit, J. Pyun, J. M. J. Frechet, K. B. Sharpless, V. V. Fokin, Efficiency and fidelity in a click-chemistry route to triazole dendrimers by the copper(I)-catalyzed ligation of azides and alkynes, Angew. Chem. Int. Ed. 43 (2004) 3928-3932, doi: http://dx.doi.org/10.1002/anie.200454078; b) P. Wu, M. Malkoch, J. N. Hunt, R. Vestberg, E. Kaltgrad, M. G. Finn, V. V. Fokin, K. B. Sharpless, C. J. Hawker, Multivalent, bifunctional dendrimers prepared by click chemistry, Chem. Commun. (2005) 5775-5777, doi: http://dx.doi.org/10.1039/ b512021g; c) B. A. Laurent, S. M. Grayson, An efficient route to well-defined macrocyclic polymers via "click" cyclization, J. Am. Chem. Soc. 128 (2006) 4238-4239, doi: http://dx. doi.org/10.1021/ja0585836.

6. I. Bae, H Han, S. Chang, Highly efficient one-pot synthesis of $\mathrm{N}$-sulfonylamidines by $\mathrm{Cu}$-catalyzed three-component coupling of sulfonyl azide, alkyne, and amine, J. Am. Chem. Soc. 127 (2005) 2038-2039, doi: http://dx.doi.org/10.1021/ ja0432968.

7. a) E. J. Yoo, M. Ahlquist, S. H. Kim, I. Bae, V. V. Fokin, K. B. Sharpless, S. Chang, Copper-catalyzed synthesis of N-Sulfonyl-1,2,3-triazoles: Controlling selectivity, Angew. Chem. Int. Ed. 46 (2007) 1730-1733, doi: http://dx.doi.org/10.1002/ anie.200604241; b) E. J. Yoo, M. Ahlquist, I. Bae, K. B. Sharpless, V. V. Fokin, S. Chang, Mechanistic studies on the Cu-catalyzed three-component reactions of sulfonyl azides, 1-alkynes and amines, alcholos or water: Dichotomy via a common pathway, J. Org. Chem. 73 (2008) 5520-5528, doi: http://dx.doi.org/10.1021/jo800733p; c) S. J. Hwang, S. H. Cho, S. Chang, Evaluation of catalytic activity of copper salts and their removal processes in the three-component reactions, Pure Appl. Chem. 80 (2008) 873-879, doi: http:// dx.doi.org/10.1351/pac200880050873.

8. a) S. H. Cho, E. J. Yoo, I. Bae, S. Chang, Copper-catalyzed hydrative amide synthesis with terminalkyne, sulfonyl azide and water, J. Am. Chem. Soc. 127 (2005) 16046-16047, doi: http://dx.doi.org/10.1021/ja056399e; b) M. P. Cassidy, J. Raushel, V. V. Fokin, Practical synthesis of amides from in situ generated copper(I) acetylides and sulfonyl azides. Angew. Chem., Int Ed. 45 (2006) 3154-3157, doi: http://dx- .doi.org/10.1002/anie.200503805; c) S. H. Cho, S. Chang, Rate accelerated nonconventional amide synthesis in water: A practical catalytic aldol-surrogate reaction, Angew. Chem., Int. Ed. 46 (2007) 1897-1900, doi: http://dx.doi. org/10.1002/anie.200604358; d) S. H. Cho, S. J. Hwang, S. Chang, Copper-catalyzed three component reaction of 1-alkynes, sulfonyl azides and water: N-(4-acetamidosulfony)-2-phenylacetamide, Org. Synth. 85 (2008) 131-137, doi: http://dx.doi.org/10.15227/orgsyn.085.0131.

9. S. H. Cho, S. Chang, Room temperature copper-catalyzed 2 -functionalization of pyrrole rings by a three-component coupling reaction, Angew. Chem., Int. Ed. 47 (2008) 28362839, doi: http://dx.doi.org/10.1002/anie.200705940.

10. a) V. O. Rodionov, V. V. Fokin, M. G. Finn, Mechanism of the ligand-free $\mathrm{Cu}$-catalyzed azide-alkyne cycloaddition reaction, Angew. Chem. Int. Ed. 44 (2005) 2210-2215, doi: http:// dx.doi.org/10.1002/anie.200461496; b) M. Ahlquist, V. V. Fokin, Enhanced reactivity of dinuclear copper(I) acetylides in dipolar cycloadditions, Organometallics 26 (2007) 43894891, doi: http://dx.doi.org/10.1021/om700669v.

11. F. Himo, T. Lovell, R. Hilgraf, V. V. Rostovtsev, L. Noodleman, K. B. Sharpless, V. V. Fokin, Copper(I)-catalyzed synthesis of azoles. DFT Study predicts unprecedented reactivity and intermediates, J. Am. Chem. Soc. 127 (2005) 210-216, doi: http://dx.doi.org/10.1021/ja0471525.

12. a) C. Fromont, S. Masson, Reactivity of $N$-phenyl silylated ketenimines with electrophilic reagents, Tetrahedron $\mathbf{5 5}$ (1999) 5405-5408, doi: http://dx.doi.org/10.1016/S00404020(99)00219-7; b) F. P. Cossio. A. Arrieta, B. Leccea, M. Alajarin, A. Vidal, F. Tovar, Highly efficient induction of chirality in intermolecular [2 + 2] cycloadditions between ketenimines and imines, J. Org. Chem. 65 (2000) 3633-3643, doi: http://dx.doi.org/10.1021/jo991826q; c) A. Vidal, M. Alajarin, M. - M. Ortin, First radical addition onto ketenimines. A novel synthesis of indoles, Tetrahedron Lett. 44 (2003) 3027-3030, doi: http://dx.doi.org/10.1021/ja0471525.

13. J. Barker, M. Kilner, The coordination chemistry of the amidine ligand, Coord. Chem. Rev. 133 (1994) 219-300, doi: http://dx.doi.org/10.1016/0010-8545(94)80059-6.

14. P. Sienkiewicz, K. Bielawski, A. Bielawska, J. Pałka, Inhibition of collagen and DNA biosynthesis by a novel amidine analogue of chlorambucil is accompanied by deregulation of beta1-integrin and IGF-I receptor signaling in MDA-MB 231 cells, Environ. Toxicol. Pharmacol. 20 (2005) 118-124, doi: http://dx.doi.org/10.1016/j.etap.2004.11.001.

15. a) M. W. Partridge, A. Smith, Cyclic amidines. Part XXIV. Cyclisation of $N$-allyl- $N^{\prime}$-arylacetamidines to imidazolines, dihydroquinazolines, and dihydrobenzodiazepines,J. Chem. Soc., Perkin Trans. 1 (1973) 453-456, doi: http://dx.doi. org/10.1039/p19730000453; b) A. J. Hill, J. V. Johnston, Amidines derived from ethylendiamine, I. diamidines, J. Am. Chem. Soc. 76 (1954) 920-922, doi: http://dx.doi. org/10.1021/ja01632a092; (c) H. G. Mandel, A. J. Hill, The conversion of formamides into formamidines, J. Am. Chem. Soc. 76 (1954) 3978-3982, doi: http://dx.doi.org/10.1021/ ja01644a034.

16. A. A. Aly, A. M. Nour El-Din, Functionality of amidines and amidrazones, Arkivoc 1 (2008) 153-194, doi: http://dx.doi. org/10.3998/ark.5550190.0009.106.

17. a) R. Roger, D. G. Neilson, The chemistry of imidates, Chem. Rev. 61 (1961) 179-211, doi: http://dx.doi.org/10.1021/ cr60210a003; b) F. C. Schaefer, G. A. Peters, Base catalyzed reactions of nitriles with alcohols. A convenient route to imidates and amidine salts, J. Org. Chem. 26 (1961) 412418, doi: http://dx.doi.org/10.1021/jo01061a034; c) R. S. Garigipati, An efficient conversion of nitriles to amidines, Tetrahedron Lett. 31 (1990) 1969-1972, doi: http://dx.doi. 
org/10.1016/S0040-4039(00)88891-7; d) R. A. Moss, W. Ma, D. C. Merrer, S. Xue, Conversion of "obstinate" nitriles to amidines with Garigipati's reaction, Tetrahedron Lett. 36 (1995) 8761-8764, doi: http://dx.doi.org/10.1016/00404039(95)01925-8.

18. J. Kim, S. Y. Lee, Y. Dou, S. Chang, Synthetic utility of ammonium salts in a Cu-catalyzed three component reaction as a facile coupling partner, J. Org. Chem. 73 (2008) 9454-9457, doi: http://dx.doi.org/10.1021/jo802014g.

19. S. Mandal, H. M. Gauniyal, K. Pramanik i B. Mukhopadhyay, Glycosylated N-sulfonylamidines: Highly efficient copper-catalyzed multicomponent reaction with sugar alkynes, sulfonyl azides, and amines, J. Org. Chem. 72 (2007) 97539756, doi: http://dx.doi.org/10.1021/jo701565m.

20. X. Xu, Z. Ge, D. Cheng, L. Me, C. Lu, Q. Zhang, N. Yao, X. Li, $\mathrm{CuCl} / \mathrm{CCl}_{4}$-promoted convenient synthesis of sulfonyl amidines from tertiary amines and sulfonyl azides, Org. Lett. 12 (2010) 897-899, doi: http://dx.doi.org/10.1021/ol1000236.

21. I. Yavari, S. Ahmadian, M. Ghazanfarpur-Darjani, Y. Solgi, Formation of sulfonylamidines by copper-catalyzed coupling of sulfonyl azides, terminal alkynes, and trialkylamines, Tetrahedron Lett. 52 (2011) 668-670, doi: http://dx.doi. org/10.1016/j.tetlet.2010.11.135.

22. S. H. Kim, D. Y. Jung, S. Chang, Phosphoryl azides as versatile new reaction partners in the $\mathrm{Cu}$-catalyzed three-component couplings, J. Org. Chem. 72 (2007) 9769-9771, doi: http:// dx.doi.org/10.1021/jo7016247.

23. Y. J. Kim, S. H. Kim, S. Chang, Highly efficient synthesis of $\alpha$-amino amidines from ynamides by the Cu-catalyzed three-component coupling reactions, Tetrahedron. Lett.
49 (2008) 1745-1749, doi: http://dx.doi.org/10.1016/j.tetlet.2008.01.073.

24. D. G. Neilson, Imidates including cyclic imidates u S. Patai (ur.), The chemistry of Amidines and Imidates, Vol. 1, John Wiley \& sons, London, 1975, str. 385-489.

25. E. J. Yoo, I. Bae, S. H. Cho, H. Han, S. Chang, A facile access to $\mathrm{N}$-sulfonylimidates and their synthetic utility for the transformation to amidines and amides, Org. Lett. 8 (2006) 1347-1350, doi: http://dx.doi.org/10.1021/ol060056j.

26. J. M. Huphrey, A. R. Chamberlin, Chemical synthesis of natural product peptides: coupling methods for the incorporation of noncoded amino acids into peptides, Chem. Rev. 97 (1997) 2243-2266.

27. J. Wang, J. Wang, Y. Zhu, P. Lu, Y.Wang, Copper-cascade catalysis: synthesis of 3-functionalized indoles, Chem. Commun. 47 (2011) 3275-3277, doi: http://dx.doi.org/10.1039/ c0cc04922k.

28. S. J. Li, L. B. Gortler, A. Wiring, A. Battisti, S. Bank, W. D. Closson, Cleavage of sulfonamides with sodium naphthalene, J. Am. Chem. Soc. 89 (1967) 5311-5312, doi: http://dx.doi. org/10.1021/ja00996a055.

29. U. K. Nadir, R. V. Krishna, Facile cleavage of N-arylsulfonyl bond of $\mathrm{N}$-arylsulfonyl imidazolidinone with magnesium in methanol, J. Heterocyclic Chem. 41 (2004) 737-739, doi: http://dx.doi.org/10.1002/jhet.5570410514.

30. A. Yasuhara, T. Sakamoto, Deprotection of $N$-sulfonyl nitrogen-heteroaromatics with tetrabutylammonium fluoride, Tetrahedron Lett. 39 (1998) 595-596, doi: http://dx.doi. org/10.1016/S0040-4039(97)10653-0.

\section{SUMMARY}

1,3-Dipolar Cycloaddition (Part II): Three-Component Cu(I) Catalysed Click Reactions

Luka Krstulović, ${ }^{* *}$ Dijana Saftić, Josipa Matić, ${ }^{c}$ Miroslav Bajić, ${ }^{a}$ and Biserka Žinićb

The $\mathrm{Cu}(\mathrm{I})$ catalysed reaction of sulfonyl or phosphoryl azide and terminal alkyne obtains a ketenimine intermediate that reacts with nucleophiles like water, alcohols, amines, imines, pyrroles or indoles producing corresponding amides, imidates, amidines and substituted heterocycles, in one reaction step. These selective reactions are characterised by mild reaction conditions (room temperature, presence of air and water), without steric or electron influence of substituents on the reaction outcome.

\section{Keywords}

Alkyne, azide, click chemistry, copper, three-component reaction

\footnotetext{
a Department of Chemistry and Biochemistry, Faculty of Veterinary Medicine, University of Zagreb, Heinzelova 55, 10000 Zagreb, Croatia

${ }^{\mathrm{b}}$ Laboratory of Supramolecular and Nucleoside Chemistry, Division of Organic Chemistry and Biochemistry, Ruđer Bošković Institute, Bijenička cesta 54, 10000 Zagreb, Croatia

' Laboratory for the study of interactions of biomacromolecules, Division of Organic Chemistry and Biochemistry, Ruđer Bošković Institute, Bijenička cesta 54, 10000 Zagreb, Croatia
}

Review Received July 8, 2014 Accepted September 2, 2014 